\title{
Impaired glucose regulation in adults in Jamaica: who should have the oral glucose tolerance test?
}

\author{
Lincoln A. Sargeant, ${ }^{1}$ Michael S. Boyne, ${ }^{1}$ Franklyn I. Bennett, ${ }^{1}$ \\ Terrence E. Forrester, ${ }^{1}$ Richard S. Cooper, ${ }^{2}$ and Rainford J. Wilks ${ }^{1}$
}

Suggested citation: Sargeant LA, Boyne MS, Bennett FI, Forrester TE, Cooper RS, Wilks RJ. Impaired glucose regulation in adults in Jamaica: who should have the oral glucose tolerance test? Rev Panam Salud Publica. 2004;16(1):35-42.

ABSTRACT Objective. To compare the 1999 World Health Organization (WHO) fasting plasma glucose (FPG) criteria and the WHO 2-hour post-challenge glucose (2hPG) criteria during an oral glucose tolerance test (OGTT) in identifying adults in Jamaica with hyperglycemia. As the OGTT is not commonly used in clinical practice, factors associated with the failure of the FPG criteria to detect persons with impaired $2 h P G$ were investigated.

Methods. A random sample of 2096 adults, 25-74 years old, living in the town of Spanish Town, Jamaica, was evaluated for diabetes. After excluding 215 individuals for reasons such as missing data, the remaining 1881 persons were composed of 187 who were previously known to have diabetes and 1694 who were screened for diabetes with both FPG and $2 \mathrm{hPG}$. Results. The FPG criteria detected 83 cases of diabetes, compared to 72 by the $2 \mathrm{hPG}$ criteria. The kappa statistic comparing the two criteria was 0.31 (95\% confidence interval: 0.28 0.34 ), indicating fair agreement. There were 261 cases of impaired glucose tolerance (IGT) and 92 cases of impaired fasting glucose (IFG). In those 92 with IFG, an OGTT would identify 34 cases of IGT and 14 cases of diabetes. Of those classified as normoglycemic by FPG criteria, $14 \%$ of them had IGT or diabetes by $2 \mathrm{hPG}$ criteria. The factors predicting the likelihood of nondetection of impaired glucose tolerance or diabetes by FPG were age, body mass index, central obesity, systolic blood pressure, and female sex. By receiver operating characteristic curve analysis, an FPG of $5.1 \mathrm{mmol} / \mathrm{L}$ would predict a $2 \mathrm{hPG} \geq 7.8 \mathrm{mmol} / \mathrm{L}$.

Conclusions. A few individuals classified as normal on FPG will have IGT or diabetes, and an OGTT will be needed to identify them. The yield of IGT detected by screening in Jamaica can be improved by lowering the threshold for IFG or by using clinical information to identify high-risk individuals.

Key words Diabetes mellitus, blood glucose, glucose intolerance, glucose tolerance test, mass screening, Jamaica.

University of the West Indies, Mona Campus, Tropical Medicine Research Institute, Mona, Kingston, Jamaica. Send correspondence to: Michael Boyne, Tropical Metabolism Research Unit, Tropical Medicine Research Institute, University of the West Indies, Mona, Kingston 7, Jamaica; telephone:
(876) 927 1884; fax: (876) 977 0632; e-mail: michael boyne@uwimona.edu.jm

2 Loyola University Stritch School of Medicine, Department of Preventive Medicine and Epidemiology, Chicago, Illinois, United States of America.
People with impaired glucose regulation (impaired fasting glucose (IFG) and/or impaired glucose tolerance (IGT)) are at risk of developing type 2 diabetes (1-3). This risk can be amelio- 
rated by lifestyle interventions as well as drug therapy, according to recent trials (4-6). As such, these individuals form a high-risk or prediabetic group who could benefit from proven interventions to prevent diabetes if these persons were identified. Screening for prediabetic states may be particularly indicated where the burden of diabetes is high.

In Jamaica the prevalence of diabetes is high. Among survey participants 25 to 74 years old in the town of Spanish Town the prevalence was estimated at $13.4 \%$ (7). A third of these participants had diabetes that had not been detected previously. These estimates were somewhat lower than those from an earlier population survey in Jamaica, where overall prevalence was $17.9 \%$, with a $48 \%$ frequency of undiagnosed diabetes (8). The prevalence of IGT in Spanish Town was 13.7\% (7).

The World Health Organization (WHO) in 1999 proposed both fasting plasma glucose (FPG) criteria and 2hour post-challenge glucose (2hPG) criteria on an oral glucose tolerance test (OGTT) for diagnosing disorders of impaired glucose regulation (1). However, the WHO noted that IFG and IGT were not interchangeable categories. The OGTT is costly, timeconsuming, and inconvenient, and alternative screening strategies have been proposed to limit its use (9).

There were three main aims for this study:

1. To compare the performance of the FPG and 2hPG criteria in identifying individuals with undiagnosed diabetes and lesser degrees of glucose impairment.

2. To investigate the implications of relying solely on the fasting criteria for diagnosis, and the factors associated with increased risk of missing individuals with impaired glucose tolerance and diabetes (especially given the relative inconvenience and uncommon use of the OGTT in clinical practice).

3. To examine two strategies for identifying people with IGT or diabetes whose FPG was normal $(<6.1$ $\mathrm{mmol} / \mathrm{L})$.

\section{METHODS}

\section{Subjects and measurements}

Participants were recruited to an ongoing survey of hypertension, diabetes, and chronic disease in Spanish Town, Jamaica. A probability proportionate to size cluster sampling technique was used to randomly select participants in five 10-year age strata (25-34, 35-44, 45-54, 55-64, 65-74), with equal proportions of men and women in each age stratum (7). The clusters were enumeration districts derived from the 1991 census, which was the most recent one at the time of our research study. Individuals residing in selected clusters were contacted and recruited by research nurses doing house-to-house visitations. Individuals were invited to participate if they were 25-74 years old. A participation rate of $60 \%$ was achieved. Approximately $90 \%$ of Jamaicans identify their race as black, and some $7 \%$ as mixed (i.e., black mixed with Chinese, Indian, or Caucasian). The protocol was reviewed and approved by the Ethics Committee of the University of the West Indies, Mona.

Participants attended a centrally located clinic at the Spanish Town Hospital, after an overnight fast of 12-14 hours. They completed an intervieweradministered questionnaire covering their health and lifestyle practices and personal and family history of disease. The question "Have you ever been told by a doctor or health professional that you had diabetes or sugar?" was used to identify participants with a history of diabetes.

Blood pressure (BP), height, weight, waist circumference, and hip circumference were measured using a standardized protocol $(10,11)$. BP was measured to the nearest $2 \mathrm{mmHg}$ as the first and the fifth Korotkoff phases, using a standard mercury sphygmomanometer. Three measurements were taken at one-minute intervals in the sitting position after the participant had been sitting for five minutes. Body mass index (BMI) was calculated as weight in kilograms divided by height in meters squared $\left(\mathrm{kg} / \mathrm{m}^{2}\right)$. The waist-to-hip ratio
(WHR) was calculated as waist circumference divided by hip circumference, both measured with a retractable steel tape to the nearest $0.1 \mathrm{~cm}$.

Individuals without known diabetes were screened for diabetes by both FPG and by OGTT. Fasting venous samples were collected in heparinized and fluoridated tubes for plasma glucose concentration. Participants then had an OGTT, where they consumed a 75-g glucose solution over a period of two to three minutes. A blood sample was drawn 120 minutes after ingesting the glucose (i.e., 2hPG).

Samples were frozen and transported to a single laboratory, where plasma glucose concentration was estimated using the glucose oxidase test within 24 hours. Cholesterol (total lipoprotein and high-density lipoprotein (HDL)) and triglycerides were measured by enzymatic techniques using an Abbott VP Biochromatic Analyzer (Abbott, Irving, Texas, United States of America). Low-density lipoprotein (LDL) cholesterol was calculated by the Friedewald formula (12).

In total, 2096 subjects were recruited between September 1993 and March 1999 and evaluated for diabetes. Of the 2 096, 22 subjects were excluded: 2 who were unsure of a personal history of diabetes, 7 women who had a history of gestational diabetes, and 13 who did not answer the question on their diabetes status. A further 193 (106 men and 87 women) did not have samples for both fasting and 2-hour glucose concentration (for reasons such as subject refusal, broken blood tubes, etc.) and were excluded from further analysis. Men without these blood results were significantly younger (mean age, 41.0 years; standard deviation (SD), 12.4 years) than those with glucose values (mean, 47.1 years; SD, 14.6 years $)(P<0.0001)$. Mean BMI was not statistically different $(P=0.98)$. Women without these blood results did not differ by age $(P=$ $0.55)$ or BMI $(P=0.19)$ from those with results. With these exclusions, there were 1881 persons eligible for analysis, of which 187 had known diabetes and 1694 were screened for diabetes with both FPG and 2hPG. 


\section{Definitions}

Known diabetes was defined as a diagnosis made by a doctor or other health professional based on the participants' questionnaire information. The majority (61\%) of individuals with known diabetes reported their diabetes management was principally by drug treatment, and a further $30 \%$ reported using only a diabetic diet. In those without a known history of diabetes, the FPG and/or 2hPG were used to classify glycemic status. Diabetes was defined as an FPG concentration $\geq 7.0 \mathrm{mmol} / \mathrm{L}$, and IFG as 6.1 to $6.9 \mathrm{mmol} / \mathrm{L}$ (1). Individuals with fasting glucose $\leq 6.0$ $\mathrm{mmol} / \mathrm{L}$ were classified as normoglycemic by the FPG criteria. Diabetes by the $2 \mathrm{hPG}$ criteria was a $2 \mathrm{hPG}$ concentration $\geq 11.1 \mathrm{mmol} / \mathrm{L}$, and IGT was 7.8 to $11.0 \mathrm{mmol} / \mathrm{L}$. Normoglycemia was defined as a $2 \mathrm{hPG}$ concentration $<7.8$ $\mathrm{mmol} / \mathrm{L}$ (1). Hypertension was defined as systolic BP $\geq 140 \mathrm{mmHg}$ and/or diastolic BP $\geq 90 \mathrm{mmHg}$ and/or current use of antihypertensive medication.

\section{Statistical analyses}

Data were analyzed using Intercooled Stata 6.0 software (StataCorp LP, College Station, Texas, United States). The $t$ test was used to compare differences between means, and the chi-square test was used to compare differences in proportions. A $P$ value of less than 0.05 was considered statistically significant. Both FPG and 2hPG criteria were applied to individuals without known diabetes, with the assumption that each criterion was independent of the other.

The number of screen-detected cases identified by each set of criteria was added to the number of known diabetic cases to calculate the total prevalence, with the associated 95\% confidence interval (95\% CI). The kappa statistic was used to assess the concordance of the two criteria in categorizing participants with respect to glycemic status. (A kappa value of 0 indicates the agreement is due to chance, while a value of 1 indicates perfect agreement.)
Logistic regression analysis was done to find factors that predicted failure of the FPG criteria to identify individuals with undiagnosed IGT or diabetes by $2 \mathrm{hPG}$ criteria. These analyses were restricted to individuals classified as normoglycemic by FPG criteria. The variables examined were age, sex, history of hypertension, family history of diabetes (parents, siblings, or grandparents), BMI, waist circumference, WHR, systolic BP, diastolic BP, total cholesterol, HDL cholesterol, LDL cholesterol, and fasting triglycerides. These variables were examined in univariate models and retained if they were significant to $P<0.20$. The retained variables were subjected to stepwise forward logistic regression to identify the best predictors on multivariate adjustment. Waist circumference was collinear with BMI and WHR, and it was examined in similar models without the inclusion of these variables.

Retained variables that were continuous were dichotomized in order to calculate a "score" for participants. We assigned a value of 1 to each of the following four characteristics: (1) age $\geq 45$ years; (2) female sex; (3) BMI $\geq 30 \mathrm{~kg} /$ $\mathrm{m}^{2}$, waist $\geq 80 \mathrm{~cm}$ for women or $\geq 94 \mathrm{~cm}$ for men, or WHR $\geq 0.80$ for women or $\geq 0.95$ for men; and (4) systolic BP $\geq 140 \mathrm{mmHg}$. Otherwise, a value of 0 was assigned. These values were summed to give the "score," which could be a maximum of 4 .

An age of 45 years was used because of the American Diabetes Association's (ADA) recommendation to start screening in high-risk groups at this age (13). A BMI of $30 \mathrm{~kg} / \mathrm{m}^{2}$ or higher represents obesity. Cutoff points for waist circumference and for WHR were based on the respective proposals by Lean et al. (14) and by the United States Department of Agriculture (15).

We examined more complex scores based on the beta coefficients of the multivariate logistic regression models, but they did not perform better than the simple score.

Receiver operating characteristic (ROC) curves were used to examine the performance of scores that included age, sex, one or more obesity measures, and systolic BP in identifying people with normal FPG but with abnormal 2hPG. An ROC curve was also used to determine the "optimal" cutoff of FPG for detection of IGT or diabetes by $2 \mathrm{hPG}$ criteria. This cutoff point was chosen to maximize the sensitivity and specificity of FPG in predicting a $2 \mathrm{hPG}$ of $7.8 \mathrm{mmol} / \mathrm{L}$.

\section{RESULTS}

Overall, 187 of 1881 participants reported having diabetes, giving an overall prevalence of $9.9 \%$ (95\% CI: $8.6 \%-11.4 \%$ ). The prevalence of selfreported diabetes among the 738 men included in the analyses was $7.7 \%$ (95\% CI: 5.9\%-9.9\%), and among the 1143 women it was $11.4 \%$ (95\% CI: 9.6\%-13.4\%). Among both the men and women, persons known to have diabetes were older and had higher BMI, waist circumference, WHR, and blood pressure values in comparison to those who were screened. Persons with known diabetes also had a higher prevalence of self-reported hypertension. These differences were independent of age (Table 1).

Table 2 shows the proportions crossclassified by the FPG and 2hPG criteria in individuals without physiciandiagnosed diabetes. Fifty-five percent of those classified as having diabetes by the FPG criteria were similarly classified by the 2hPG. A higher proportion of those classified diabetic by the $2 \mathrm{hPG}$ criteria $(64 \%)$ were also diabetic by the FPG criteria. Few who were classified as normoglycemic on either set of criteria were found to be diabetic by the other criteria. Misclassification was greatest in the intermediate glycemic categories. Only $13 \%$ of people with IGT had IFG, while $37 \%$ of those classified as having IFG also had IGT. The overall kappa statistic was 0.31 (95\% CI: 0.28-0.34), indicating fair agreement.

Slightly more people were found to have diabetes by using the FPG criteria than by using the $2 \mathrm{hPG}$ criteria (Table 3). The absolute difference in prevalence of screen-detected diabetes by these two criteria was small: $1.2 \%$ 
TABLE 1. General characteristics of participants in study of impaired glucose regulation in adults in Jamaica, 1993-1999a

\begin{tabular}{|c|c|c|c|c|c|c|c|c|}
\hline \multirow[b]{3}{*}{ Age (years) } & \multicolumn{4}{|c|}{ Men } & \multicolumn{4}{|c|}{ Women } \\
\hline & \multicolumn{2}{|c|}{$\begin{array}{l}\text { Known } \\
\text { diabetes } \\
(n=57)\end{array}$} & \multicolumn{2}{|c|}{$\begin{array}{c}\text { Screened } \\
\text { participants } \\
(n=681)\end{array}$} & \multicolumn{2}{|c|}{$\begin{array}{c}\text { Known } \\
\text { diabetes } \\
(n=130)\end{array}$} & \multicolumn{2}{|c|}{$\begin{array}{c}\text { Screened } \\
\text { participants } \\
(n=1013)\end{array}$} \\
\hline & 55.7 & (11.9) & 46.3 & $(14.6)$ & 57.5 & (10.9) & 44.6 & $(13.0)$ \\
\hline Body mass index $\left(\mathrm{kg} / \mathrm{m}^{2}\right)$ & 25.7 & $(4.6)$ & 23.7 & $(4.2)$ & 29.0 & $(6.6)$ & 27.9 & $(6.4)$ \\
\hline Waist (cm) & 88.7 & (11.7) & 80.3 & (11.5) & 87.7 & (12.0) & 82.9 & (13.0) \\
\hline Waist-to-hip ratio & 0.90 & $(0.06)$ & 0.84 & $(0.07)$ & 0.84 & $(0.08)$ & 0.79 & $(0.06)$ \\
\hline Systolic blood pressure (mmHg) & 130.4 & (19.5) & 120.3 & (20.3) & 131.5 & $(25.5)$ & 119.2 & $(20.8)$ \\
\hline Diastolic blood pressure (mmHg) & 75.6 & $(13.9)$ & 69.0 & $(14.3)$ & 70.9 & (13.4) & 68.7 & $(13.9)$ \\
\hline Prevalence of known hypertension $(\%)^{b}$ & 49.1 & $(28 / 57)$ & 18.4 & $(123 / 669)$ & 62.3 & $(81 / 130)$ & 29.4 & $(294 / 1001)$ \\
\hline
\end{tabular}

a Unless otherwise stated, the results are mean and standard deviation.

${ }^{b}$ The denominator in each fraction is the number of individuals who confirmed their hypertension status.

TABLE 2. Frequency of glucose status categories by 1999 World Health Organization fasting plasma glucose (FPG) and 2-hour post-challenge glucose (2hPG) criteria in individuals without a physician diagnosis of diabetes in study of impaired glucose regulation in adults in Jamaica, 1993-1999

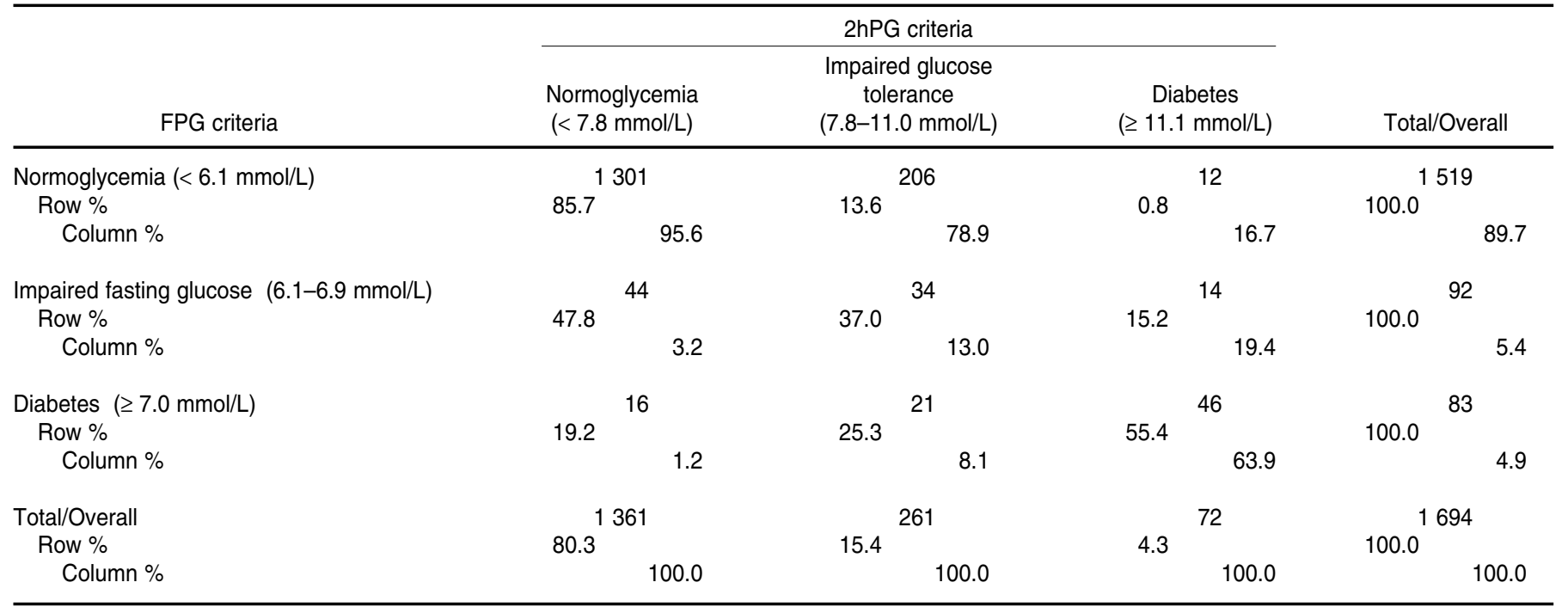

in men, $0.2 \%$ in women, and $0.6 \%$ overall. The proportion of undetected diabetes was $34 \%$ overall by the FPG criteria and $31 \%$ by $2 \mathrm{hPG}$.

The FPG criteria classified as normoglycemic 218 individuals with either IGT (206 persons) or diabetes (12 persons) by 2hPG criteria. The 149 women in this group were significantly more obese than were the men; the women had a mean BMI of 29.0 $(\mathrm{SD}=6.0)$ vs. $24.5(\mathrm{SD}=4.9)$ for the men $(P<0.0001)$. This difference re- mained significant after adjustment for WHR. Table 4 shows factors that were predictive of missing this at-risk group when using only the FPG criteria. Women were at greater risk compared to men for being missed. Higher values for age, BMI, WHR, waist circumference, and systolic BP were also predictors. A history of hypertension, a family history of diabetes, and diastolic blood pressure were not significant predictors of being missed. None of the lipid measures was retained since they either were not significant in univariate models or were not independent of obesity variables.

We examined two approaches to screen for IGT and diabetes in people with FPG $<6.1 \mathrm{mmol} / \mathrm{L}$. Figure 1 shows the ROC curve for detection of $2 \mathrm{hPG} \geq 7.8 \mathrm{mmol} / \mathrm{L}$ using FPG. The "optimal" cutoff of FPG was 5.1 $\mathrm{mmol} / \mathrm{L}$. This cutoff had a sensitivity of $73.0 \%$ and a specificity of $70.6 \%$. There were 468 people with FPG between 5.1 and $6.1 \mathrm{mmol} / \mathrm{L}$; of these 
TABLE 3. Total prevalence (with $95 \%$ confidence interval (CI)) of diabetes using 1999 World Health Organization fasting plasma glucose (FPG) and 2-hour post-challenge glucose (2hPG) criteria in study of impaired glucose regulation in adults in Jamaica, 1993-1999

\begin{tabular}{lccccc}
\hline & \multicolumn{2}{c}{ FPG criteria } & & \multicolumn{2}{c}{ 2hPG criteria } \\
\cline { 2 - 3 } & Prevalence & $95 \% \mathrm{Cl}$ & & Prevalence & $95 \% \mathrm{Cl}$ \\
\hline Men & 11.4 & $9.2-13.9$ & & 10.2 & $8.1-12.6$ \\
Women & 16.3 & $14.2-18.5$ & & 16.1 & $14.0-18.4$ \\
25-44 years & 5.9 & $4.5-7.6$ & & 5.2 & $3.9-6.9$ \\
45-74 years & 22.8 & $20.1-25.6$ & & 22.2 & $19.6-25.0$ \\
Overall & 14.4 & $12.8-16.0$ & & 13.8 & $12.2-15.4$ \\
\hline
\end{tabular}

TABLE 4. Risk (odds ratio (OR) and $95 \%$ confidence interval $(\mathrm{CI})$ ) of nondetection of impaired glucose tolerance or diabetes by 1999 WHO $2 \mathrm{hPG}$ criteria using fasting plasma glucose criteria only, study of impaired glucose regulation in adults in Jamaica, 1993-1999a

\begin{tabular}{|c|c|c|c|}
\hline Variable & OR & $95 \% \mathrm{Cl}$ & $P$ value \\
\hline Age (per 10-year increase) & 1.46 & $1.28-1.66$ & $<0.001$ \\
\hline Sex $($ male $=0$, female $=1)$ & 1.86 & $1.27-2.75$ & 0.002 \\
\hline Body mass index (per $5-\mathrm{kg} / \mathrm{m}^{2}$ increase) & 1.22 & $1.06-1.41$ & 0.005 \\
\hline Waist-to-hip ratio (per 0.05 increase) & 1.15 & $1.01-1.31$ & 0.031 \\
\hline Systolic blood pressure (per 10-mmHg increase) & 1.09 & $1.01-1.17$ & 0.025 \\
\hline Waist circumference (per 10-cm increase) ${ }^{b}$ & 1.28 & $1.14-1.45$ & $<0.001$ \\
\hline
\end{tabular}

a Multivariate models were used and variables have been selected and given in the order of entry into the model. Odds ratios for model with age, sex, body mass index (BMI), waist-to-hip ratio (WHR), and systolic blood pressure are shown. Odds ratios for other covariates in the model with waist circumference substituted for BMI and WHR were similar to those reported. ${ }^{b}$ Separate model with age, sex, and systolic BP as other covariates.
468,117 of them had IGT and 11 had diabetes by the $2 \mathrm{hPG}$ criteria. Hence, lowering the threshold for IFG to 5.1 $\mathrm{mmol} / \mathrm{L}$ would identify $59 \%$ of those with IGT or diabetes by $2 \mathrm{hPG}$ criteria who would be missed at the current threshold of $6.1 \mathrm{mmol} / \mathrm{L}$.

Among the 92 participants with IFG as currently defined, an OGTT would identify 34 cases of IGT (37\%) and 14 cases of diabetes $(15 \%)$. Based on the results shown in Table 4, an approach to detecting abnormal OGTT results in those with normal FPG is proposed in Figure 2. We investigated several scores that included age, sex, systolic $\mathrm{BP}$, and either one or more of BMI, WHR, and waist circumference. All scores had similar areas under the ROC curve, ranging from 0.66 to 0.68 . The scores identified between 140 and 167 of the missed individuals, and in all the sensitivity and specificity was maximized (i.e., around $76 \%$ and $70 \%$, respectively) at a score of 2 (i.e., presence of two or more risk factors).

This approach would require performing an OGTT in 751 individuals with FPG $<6.1 \mathrm{mmol} / \mathrm{L}$, and it would identify in this group 153 with IGT and 9 with diabetes by $2 \mathrm{hPG}$ criteria, or $74 \%$ of the 218 that would be missed if no OGTT were done (Figure 2).

\section{DISCUSSION}

FIGURE 1. Receiver operating characteristic (ROC) curve for the prediction of post-challenge glucose levels $\geq 7.8 \mathrm{mmol} / \mathrm{L}$ by fasting plasma glucose (FPG) in adults in Jamaica, 1993-1999

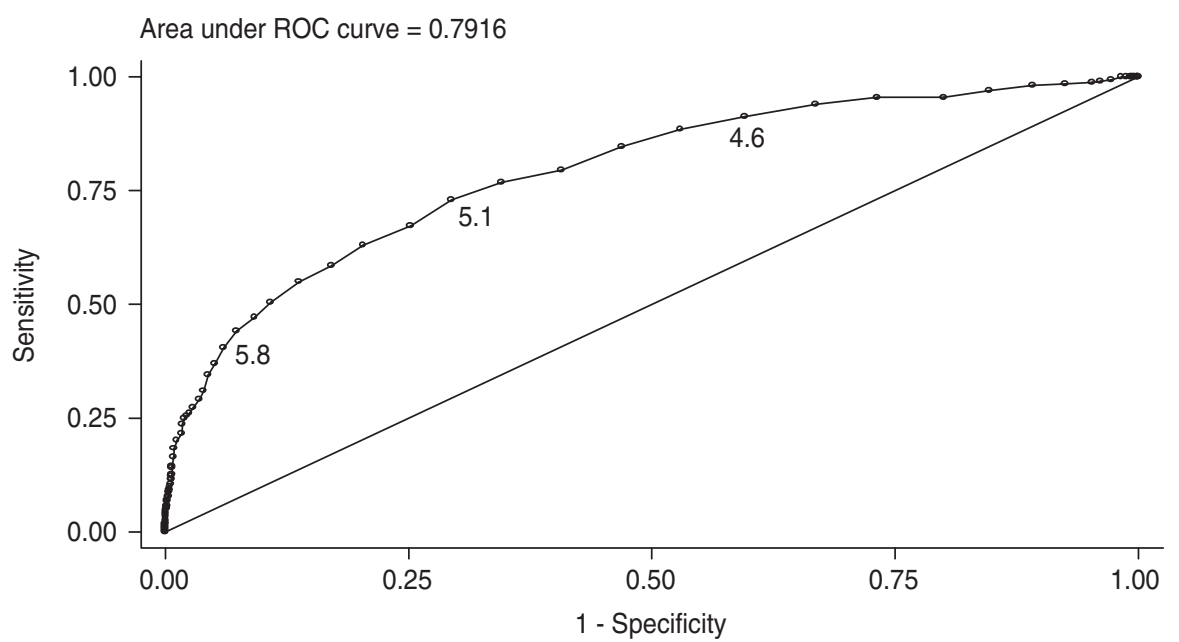

The numbers on the curving line are the FPG threshold values in $\mathrm{mmol} / \mathrm{L}$. A perfect test would have $100 \%$ specificity, and would be indicated by a point in the upper left-hand corner. The optimal cutoff point was $5.1 \mathrm{mmol} / \mathrm{L}$. The curve for a test with no discriminatory power would appear as the diagonal line from the lower left corner to the upper right corner.
The WHO has retained the OGTT as a diagnostic test for diabetes because of the variability in the concordance between the ADA criteria (13) and the 1985 WHO criteria worldwide $(1,16)$. Using the fasting glucose as the sole diagnostic test is much simpler and reflects more closely what happens in clinical practice. However, IGT is a well-established risk factor for type 2 diabetes and cardiovascular disease $(17,18)$. In addition, there are proven interventions that reduce risk in people with IGT $(4-6,19)$.

Our findings suggest that the FPG criteria resulted in a similar proportion of screen-detected diabetes compared to the $2 \mathrm{hPG}$ criteria. However, there was discordance in the intermediate glycemic categories, where IGT 
FIGURE 2. Algorithm for use of the oral glucose tolerance test in screening in adults in Jamaica, 1993-1999

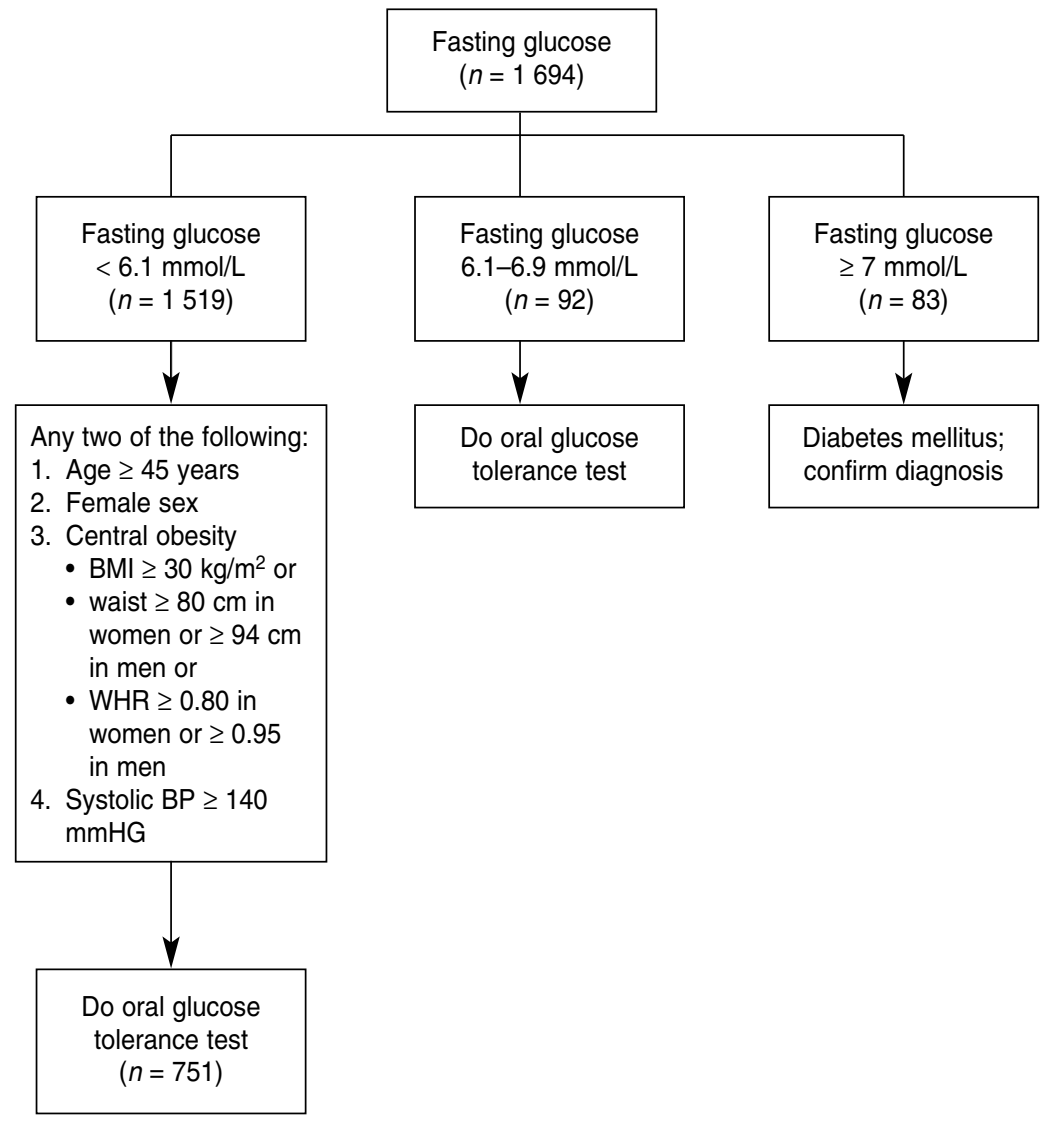

and IFG were found not to be equivalent categories. This is in keeping with other studies (20-22). The likelihood and consequences of missing individuals with impairment of glucose metabolism by using only the FPG criteria are potentially greater than would occur if only the OGTT were performed. The factors predicting the likelihood of missing these individuals by the FPG criteria were increased for female sex and for higher values for age, BMI, central obesity, and systolic blood pressure.

This result is important because higher age, BMI, and central obesity are associated with progression of IGT to diabetes $(23,24)$. Increased systolic blood pressure, as a component of the insulin resistance syndrome (25), also indicates increased risk for future cardiovascular disease in these indi- viduals. The prevalence of diabetes is higher in women, who are also more likely to remain undiagnosed if FPG criteria are used alone.

From the public health point of view, both criteria produce acceptable results in terms of detecting undiagnosed diabetes. Jamaica does not have a national screening policy for diabetes, but opportunistic screening is commonly practiced. Those who seek medical attention, particularly for chronic diseases such as hypertension, are more likely to be screened for diabetes than are other persons. Hypertension is more common among women and the elderly in Jamaica. It is noteworthy that the largest differences in undetected diabetes between the criteria were found among men and those under the age of 45 years. Population screening using fasting glucose only is likely to be a more convenient and costeffective strategy in identifying persons with diabetes. However, from a clinical perspective, $14 \%$ of individuals at clear risk for diabetes and diabetic complications would be classified as normal if only fasting glucose were used.

In addition, just over half of those identified as having IFG also have diabetes or IGT. People with IFG and IGT together have much greater risk for incident diabetes than do those with either isolated IFG or isolated IGT (3). Performing OGTT in people with IFG would help to better characterize their risk, and it is recommended by the WHO (1). The concern, however, is with those who would be deemed normal by current FPG criteria.

We explore two approaches to addressing this problem. The first would be to lower the threshold for IFG to 5.1 $\mathrm{mmol} / \mathrm{L}$. This approach is suggested by the American Diabetes Association, at least for the diagnosis of diabetes; the ADA recently lowered the threshold of the IFG to $5.6 \mathrm{mmol} / \mathrm{L}(26)$. Lowering the threshold to $5.1 \mathrm{mmol} /$ L would mean doing an additional 468 OGTTs over the currently recommended approach and would identify $59 \%$ of those misclassified with respect to $2 \mathrm{hPG}$ criteria. The second approach would be to keep the FPG criteria as currently defined and use clinical information to identify people with normal FPG for screening with the OGTT. We propose that persons should be given an OGTT if they have a fasting glucose of $<6.1 \mathrm{mmol} / \mathrm{L}$ and have two or more of the following four characteristics: (1) age $\geq 45$ years; (2) female sex; (3) central obesity as seen by BMI $\geq 30 \mathrm{~kg} / \mathrm{m}^{2}$, or waist $\geq 80 \mathrm{~cm}$ in women or $\geq 94 \mathrm{~cm}$ in men, or WHR $\geq 0.80$ for women or $\geq 0.95$ for men; or (4) systolic $\mathrm{BP} \geq 140 \mathrm{mmHg}$. These risk categories were chosen to facilitate practical application of our results. This approach would require doing more OGTTs, but it would also have a higher yield in diagnosing diabetes than would merely lowering the FPG threshold.

One strength of the study is that the sample is sufficiently large to allow for 
stable estimates of prevalence of impaired glucose regulation. However, there is likely to be some selection bias with an overall participation rate of $60 \%$. Our results were similar to those of surveys done in sub-Saharan Africa, suggesting than any selection bias is unlikely to invalidate our findings $(22,27)$.

The study is also population based, and the sample was selected by cluster sampling methodology to increase representativeness. The Spanish Town community is thought to be representative of the urban demographic profile of Jamaica and was chosen on the advice of the Statistical Institute of Jamaica because of this. Our findings are therefore likely to be generalizable to the adult population of Jamaica, but they should also apply to other Caribbean countries and developing countries in general that share similar socioeconomic and epidemiologic features (7).

One potential limitation of the study, however, is the fact that the OGTT has poor reproducibility. In one study, the intra-individual coefficient of variation was $16.7 \%$ when a second OGTT was performed two to six weeks later (28). Some of the variability may be due to differences in the conditions surrounding the performance of the test such as inadequate carbohydrate loading for the three days prior to the test, duration of fasting, and level of physical activity preceding the test. The poor reproducibility may also re- flect the inherent variability of glucose homeostasis. It is not clear how our results might have changed on repeat testing.

However, if this variability is random, the overall reclassification of individuals within groups would probably result in an unchanged prevalence of IGT and diabetes. Also, prior epidemiologic data on incidence, prevalence, and sequelae of diabetes mellitus utilized a single OGTT performed on each individual $(1,13,29,30)$. Nevertheless, in clinical practice the diagnosis of diabetes should not be based on a single measure of blood glucose in asymptomatic individuals $(1,13)$. Individuals with screen-detected diabetes need confirmation by repeat testing.

While the overall prevalence of diabetes is similar with both criteria, the kappa statistic suggests that different people are being classified as cases. Since neither the FPG nor the OGTT can be considered the "gold standard" for diagnosing diabetes, the kappa statistic cannot test the relative or absolute accuracy or comparability of the two methods. Diabetes-specific outcomes, such as retinopathy, would be needed for this comparison. Repeat testing of individuals will result in reclassification of case status. For example, some individuals with IGT will be found to have diabetes on a repeat OGTT, and vice versa. Since there is variability in both the FPG and the
OGTT, it is not possible to precisely quantify the true number of clinical cases of impaired glucose regulation using single glucose measures. Therefore, the actual yield of cases meeting the clinical definition of IFG, IGT, or diabetes requires repeat testing. Consequently, there must be caution in applying the results of this survey to the clinical setting.

In summary, the FPG criteria perform well in the Jamaican population with respect to identifying undetected diabetes but may misclassify a subgroup with IGT. These individuals, classified as normal on fasting glucose, will have features of insulin resistance, and an OGTT may be needed to identify them. They are at increased risk for diabetes and its complications, and effective interventions are available to reduce this risk. The yield of screendetected IGT can be improved by lowering the threshold for IFG or by using clinical information to identify highrisk individuals. The latter approach may be a pragmatic one while the debate on the definition of IFG and IGT continues (31).

Acknowledgements. This work was supported in part by grants from the National Heart, Lung, and Blood Institute of the United States of America (HL45508 and HL47910), the European Commission, and the Wellcome Trust.

\section{REFERENCES}

1. World Health Organization. Definition, diagnosis and classification of diabetes mellitus and its complications. Report of a WHO consultation. Part 1: diagnosis and classification of diabetes mellitus. Geneva: WHO; 1999. (WHO/NCD/NCS/99.2).

2. Shaw JE, Zimmet PZ, de Courten M, Dowse GK, Chitson P, Gareeboo H, et al. Impaired fasting glucose or impaired glucose tolerance. What best predicts future diabetes in Mauritius? Diabetes Care. 1999;22:399-402.

3. de Vegt F, Dekker JM, Jager A, Hienkens E, Kostense PJ, Stehouwer CD, et al. Relation of impaired fasting and postload glucose with incident type 2 diabetes in a Dutch population: The Hoorn Study. JAMA. 2001;285: 2109-13.
4. Tuomilehto J, Lindstrom J, Eriksson JG, Valle TT, Hamalainen H, Ilanne-Parikka $P$, et al. Prevention of type 2 diabetes mellitus by changes in lifestyle among subjects with impaired glucose tolerance. N Engl J Med. 2001; 344:1343-50.

5. Knowler WC, Barrett-Connor E, Fowler SE, Hamman RF, Lachin JM, Walker EA, et al. Reduction in the incidence of type 2 diabetes with lifestyle intervention or metformin. $\mathrm{N}$ Engl J Med. 2002;346:393-403.

6. Chiasson JL, Josse RG, Gomis R, Hanefeld M, Karasik A, Laakso M. Acarbose for prevention of type 2 diabetes mellitus: the STOP-NIDDM randomised trial. Lancet. 2002;359: 2072-7.

7. Wilks R, Rotimi C, Bennett F, McFarlaneAnderson N, Kaufman JS, Anderson SG, et al.
Diabetes in the Caribbean: results of a population survey from Spanish Town, Jamaica. Diabet Med. 1999;16:875-83.

8. Ragoobirsingh D, Lewis-Fuller E, Morrison EY. The Jamaican Diabetes Survey. A protocol for the Caribbean. Diabetes Care. 1995;18: 1277-9.

9. Stern MP, Williams K, Haffner SM. Identification of persons at high risk for type 2 diabetes mellitus: do we need the oral glucose tolerance test? Ann Intern Med. 2002;136:575-81.

10. Ataman SL, Cooper R, Rotimi C, McGee D, Osotimehin B, Kadiri S, et al. Standardization of blood pressure measurement in an international comparative study. J Clin Epidemiol. 1996:49:869-77.

11. Cooper R, Rotimi C, Ataman S, McGee D, Osotimehin B, Kadiri S, et al. The prevalence 
of hypertension in seven populations of west African origin. Am J Public Health. 1997;87: 160-8.

12. Friedewald WT, Levy RI, Fredrickson DS. Estimation of the concentration of low-density lipoprotein cholesterol in plasma, without use of the preparative ultracentrifuge. Clin Chem. 1972;18:499-502.

13. American Diabetes Association. Report of the Expert Committee on the Diagnosis and Classification of Diabetes Mellitus. Diabetes Care. 1997;20:1183-97.

14. Lean ME, Han TS, Morrison CE. Waist circumference as a measure for indicating need for weight management. BMJ. 1995;311:158-61.

15. United States, Department of Agriculture, Human Nutrition Information Service, Dietary Guidelines Advisory Committee. Report of the Dietary Guidelines Advisory Committee on the Dietary Guidelines for Americans, 1990. Washington, D.C.: USDA, Department of Health and Human Services; 1990. (USDA Publication No. 261-495/20124).

16. World Health Organization. Diabetes mellitus. Report of a WHO Study Group. Geneva: WHO; 1985. (Technical Report Series 727).

17. Fuller JH, Shipley MJ, Rose G, Jarrett RJ, Keen H. Coronary-heart-disease risk and impaired glucose tolerance. The Whitehall study. Lancet. 1980;1:1373-6.

18. Alberti KG. The clinical implications of impaired glucose tolerance. Diabet Med. 1996; 13:927-37.

19. Pan $X R$, Li GW, Hu YH, Wang JX, Yang WY, An ZX, et al. Effects of diet and exercise in preventing NIDDM in people with impaired glucose tolerance. The Da Qing IGT and Diabetes Study. Diabetes Care. 1997;20:537-44.

20. de Vegt F, Dekker JM, Stehouwer CD, Nijpels G, Bouter LM, Heine RJ. The 1997 American Diabetes Association criteria versus the 1985 World Health Organization criteria for the diagnosis of abnormal glucose tolerance: poor agreement in the Hoorn Study. Diabetes Care. 1998;21:1686-90.

21. Davies MJ, Raymond NT, Day JL, Hales CN, Burden AC. Impaired glucose tolerance and fasting hyperglycaemia have different characteristics. Diabet Med. 2000;17:433-40.

22. Amoah AG. Undiagnosed diabetes and impaired glucose regulation in adult Ghanaians using the ADA and WHO diagnostic criteria. Acta Diabetol. 2002;39:7-13.

23. Edelstein SL, Knowler WC, Bain RP, Andres R, Barrett-Connor EL, Dowse GK, et al. Predictors of progression from impaired glucose tolerance to NIDDM: an analysis of six prospective studies. Diabetes. 1997;46:701-10.

24. Saad MF, Knowler WC, Pettitt DJ, Nelson RG, Mott DM, Bennett PH. The natural history of impaired glucose tolerance in the Pima Indians. N Engl J Med. 1988;319:1500-6.

25. Reaven GM. Banting lecture 1988. Role of insulin resistance in human disease. Diabetes. 1988;37:1595-607.

26. Genuth S, Alberti KG, Bennett P, Buse J, Defronzo R, Kahn R, et al. Follow-up report on the diagnosis of diabetes mellitus. Diabetes Care. 2003;26:3160-7.

27. Levitt NS, Unwin NC, Bradshaw D, Kitange HM, Mbanya JC, Mollentze WF, et al. Application of the new ADA criteria for the di- agnosis of diabetes to population studies in sub-Saharan Africa. American Diabetes Association. Diabet Med. 2000;17:381-5.

28. Mooy JM, Grootenhuis PA, de Vries $\mathrm{H}$ Kostense PJ, Popp-Snijders C, Bouter LM, et al. Intra-individual variation of glucose, specific insulin and proinsulin concentrations measured by two oral glucose tolerance tests in a general Caucasian population: the Hoorn Study. Diabetologia. 1996;39:298-305.

29. Harris MI, Flegal KM, Cowie CC, Eberhardt MS, Goldstein DE, Little RR, et al. Prevalence of diabetes, impaired fasting glucose, and impaired glucose tolerance in U.S. adults. The Third National Health and Nutrition Examination Survey, 1988-1994. Diabetes Care. 1998; 21:518-24.

30. DECODE Study Group on behalf of the European Diabetes Epidemiology Study Group. Will new diagnostic criteria for diabetes mellitus change phenotype of patients with diabetes? Reanalysis of European epidemiological data. BMJ. 1998;317:371-5.

31. Unwin N, Shaw J, Zimmet P, Alberti KG. Impaired glucose tolerance and impaired fasting glycaemia: the current status on definition and intervention. Diabet Med. 2002;19:708-23.

Manuscript received 22 July 2003. Revised version accepted for publication 20 May 2004.
RESUMEN

\section{Alteraciones del control de la glucemia: ¿a quiénes se les debe hacer la prueba de tolerancia a una dosis oral de glucosa?}

Objetivo. Comparar los criterios publicados por la Organización Mundial de la Salud (OMS) en 1999 acerca del uso de la prueba de glucemia en ayunas (PGA) y de la prueba de tolerancia a una dosis oral de glucosa con valoración a las dos horas (PTG2h) para identificar a adultos hiperglucémicos en Jamaica. Como la PTG2h no se administra normalmente en un contexto clínico, se investigaron los factores asociados con la inutilidad de la PGA para detectar a personas con hiperglucemia según la PTG2h.

Métodos. Se examinó una muestra aleatoria de 2096 adultos de 25 a 47 años de edad que vivían en la ciudad de Spanish Town, Jamaica, para determinar la presencia de diabetes. Una vez que se eliminó a 215 personas por diversos motivos, entre ellos la ausencia de datos, quedaron 1881 personas entre las cuales se encontraban 187 que se sabía de antemano que tenían diabetes y otras 1694 que fueron sometidas tanto a la PGA como a la PTG2h.

Resultados. La PGA permitió detectar 83 casos de diabetes, mientras que la PTG2h permitió detectar 72. El estadístico kappa de comparación entre los dos criterios de valoración fue de 0,31 (intervalo de confianza de 95\%: 0,28-0,34), valor que revela una concordancia moderada. Se observaron 261 casos de intolerancia a la glucosa tras la PTG2h y 92 casos de hiperglucemia en ayunas. En estas últimas 92 personas, la PTG2h sirvió para identificar 34 casos de intolerancia a la glucosa y 14 casos de diabetes. De las personas que se mostraron normoglucémicas según la PGA, 14\% tenían intolerancia a la glucosa o diabetes, según la PTG2h. Algunos factores tuvieron valor pronóstico en relación con la falta de detección de la intolerancia a la glucosa o la diabetes. Estos fueron la edad, el índice de masa corporal, la concentración de la obesidad en el tronco y el abdomen, la tensión sistólica y el sexo femenino. De acuerdo con la curva de eficacia diagnóstica, una glucemia en ayunas de 5,1 mmol/L tendría valor pronóstico con respecto a la presencia de una glucemia de $7,8 \mathrm{mmol} / \mathrm{L}$ según la PTG2h. Conclusiones. Algunas personas cuya glucemia en ayunas está dentro de lo normal tienen intolerancia a la glucosa o diabetes; por lo tanto, para identificarlas es necesario hacer la PTG2h. Se puede mejorar la detección de casos de intolerancia a la glucosa en Jamaica si se reduce el umbral de normalidad para la PGA o si se toman en cuenta los datos clínicos para identificar a las personas en alto riesgo. 